\title{
JMSR
}

\section{Selective extraforaminal nerve root block for management of lumbar radiculopathy}

\author{
Vihar S Joshi ${ }^{1}$, Naveen DS ${ }^{1,}$, and Nilesh Kumar Agrawal ${ }^{1}$ \\ ${ }^{1}$ Department of Orthopedics, JagadguruJayadevaMurugarajendra Medical College (JJMMC), Davanagere, Karnataka-577004, India
}

\begin{abstract}
Lower back pain with radiculopathy is one of the common complaints that patient presents to an orthopaedician. Study was done to assess effect of extraforaminal Selective Nerve Root Block (SNRB) in management of lumbar radiculopathy in 50 patients between December 2019 and June 2020 at Bapuji Medical College and Chigateri General Hospital, Davanagere, Karnataka, India. Extraforaminal SNRB was performed and Visual Analogue Scale (VAS) scores recorded pre procedure, immediate post procedure, one month and 6 months post procedure. Significant decrease $(\mathrm{p}<0.001)$ in VAS scores immediate post procedure by 5 or more points in $25 \%$; by $3-4$ points in $44 \%$ and $1-2$ points in $6 \%$ of the patients obtained. One month post procedure showed statistically significant results $(\mathrm{p}<0.005)$ owing to change in VAS score by $1-2$ points in $84 \%$ (42) patients and no change or increase in the VAS scores only in $10 \%(5)$ patients. VAS scores at $6^{\text {th }}$ month showed statistically significant results ( $\mathrm{p}<0.005$ ) with reduction of VAS scores in $46.34 \%$ (19), retention of VAS score 0 in $31.70 \%$ (13) and no change or increase in VAS scores in only $21.95 \%$ (9) patients. Our study concludes that extraforaminal SNRB acts as excellent diagnostic tool and therapeutic modality for immediate and long term pain management in lumbar radiculopathy. Increase in the pain scores at $6^{\text {th }}$ month $(\mathrm{p}=0.2)$ shows that recurrence of symptoms is a possibility. Further randomized control studies with larger study population, association of patient factors affecting extraforaminal SNRB would give better insight and knowledge of the factual data.
\end{abstract}

Keywords: extraforaminal selective nerve root block; lumbar radiculopathy; lumbar intervertebral disc

*Corresponding author: Dr. Naveen DS, Assistant Professor, Department of Orthopedics, Jagadguru Jayadeva Murugarajendra Medical College (JJMMC), Davanagere, Karnataka-577004, India. Mobile: +919986091144; Email: nds5959@gmail.com

Received 17 March 2021; Revised 28 May 2021; Accepted 10 June 2021; Published 18 June 2021

Citation: Vihar SJ, Naveen DS, Agrawal NK. Selective extraforaminal nerve root block for management of lumbar radiculopathy. J Med Sci Res. 2021; 9(3):147-154. DOI: http://dx.doi.org/10.17727/ JMSR.2021/9-21

Copyright: (C) 2021 Vihar SJ et al. Published by KIMS Foundation and Research Center. This is an open-access article distributed under the terms of the Creative Commons Attribution License, which permits unrestricted use, distribution, and reproduction in any medium, provided the original author and source are credited.

\section{Introduction}

Lower back pain with radiculopathy is one of the common complaints that patient presents to an orthopaedician. It is a common and benign disease that affects almost all persons with a lifetime prevalence of up to $84 \%$ [1] and defined as pain from lower back radiating to lower limb along the course of a particular lumbar nerve [2-4]. Generally, history of trauma, fall, lifting heavy weight is associated with these complaints. The condition can be managed with conservative treatment unless there is indication for surgical management. Rest, physiotherapy, nonsteroidalanti-inflammatorydrugs are initial modality of treatment, but if there is failure to alleviate pain 
with conservative management for at least six weeks, it is considered as failure of conservative management $[5,6]$. If pain persists and fails to respond to conservative treatment methods, surgery is advised [7, 8]. Immediate surgery is indicated in patients with lumbar radiculopathy associated with foot drop or bladder incontinence [9]. Causes of lumbar radiculopathy includes intervertebral disc prolapse, degenerative osteophytes, facet joint hypertrophy ligamentum flavum hypertrophy that can cause foraminal stenosis and irritation of the exiting nerve roots [10].

The compression and irritation of the exiting nerve root is caused by intervertebral disc prolapsed in approximately $90 \%$ of cases $[5,11]$. Surgical treatment varies according to the cause of the pain made post investigations and includes minimally invasive procedures such as Selective Nerve Root Block (SNRB), endoscopic laminectomy, discectomy or open procedures with fixation of the lumbar spine fractures if any $[12,13]$. SNRB is one of the management of radiculopathy due to an affected nerve root in both cervical and lumbar regions [2-3]. It is one of the treatment modality that can be used without the necessity of general anesthesia [3]. It acts as an intermediate treatment modality that is less expensive, minimally invasive, fast, easily accepted by patients that gives a time window for relief of lumbar radiculopathy pain [14]. Though, effect of SNRB as a therapeutic procedure is debatable and chances of recurrence of the lumbar radiculopathy or lumbar pain persists [15]. Steroids are chosen for its to reduce inflammation and cause numbness to the transmission of the pain in the effected nerve $[3,16]$. Methyl prednisolone based preparations [17] and triamcinolone and betamethasone based preparations [18] are ones commonly used drugs for SNRB. Local anesthetics like Lignocaine, bupivacaine are also administered along with the steroids. Steroids are injected at various sites as it exits from the intervertebral foramen. Transforaminal SNRB [19], extraforaminal selective nerve root block [20] intraepineural, extraepineural, paraepineural approaches under fluoroscopy/ computed tomography guidance are some of the common approaches for SNRB that have been found to be effective. Studies on extraforaminal SNRB are scanty and hence this study was done to assess effect of extraforaminal SNRB for management of lumbar radiculopathy.

\section{Methodology}

The study was conducted between December 2019 and June 2020 among 50 patients at Bapuji Medical College and Chigateri General Hospital, Davanagere, Karnataka, India. Patients between age group of 20 and 70 years, who presented with complaints of lower back ache and radiating pain to lower limb, diagnosed clinically to have lumbar radiculopathy without neurological and motor weakness and its pathology confirmed to be intervertebral disc prolapse affecting single lumbar nerve root post magnetic resonance imaging (MRI) and patients willing and consenting for the procedure were selected. The pain was assessed using Visual Analogue Scale (VAS) score in each patient and documented pre procedure. After thorough pre procedure planning, extraforaminal SNRB was performed in each patient using $2 \mathrm{ml}$ (80mg) of methylprednisolone (Depo-medrol) with one $\mathrm{ml} 2 \%$ plain lignocaine post lignocaine test dose, after marking the level of exiting nerve root, injecting isoionic contrast (omnipaque) under C-arm fluoroscope with needle angulated 90 degrees between pars interarticularis and transverse process. Immediate post procedure, one month and 6 month post procedure VAS score were noted, collected, documented and assessed to study the effectiveness of extraforaminal SNRB.

\section{Results}

The study was conducted in 50 patients of which $16(32 \%)$ patients were male and $34(68 \%)$ patients were female. Mean age group of the patients studied was 50.3 years. Mean age of male patients was 52.06 years (29-69) and female patients 49.47 years (2770). As per the inclusion criteria, patients between the ages of 20 to 70 years were included for study. Maximum number of both male patients (31.25\%) and female patients (29.41\%) belonged to age group 60 to 69 (Table 1 ).

Table 1: Age and sex distribution of the patients included in the study.

\begin{tabular}{|ccc|}
\hline $\begin{array}{c}\text { Age }(\text { in } \\
\text { years })\end{array}$ & Male $[n=16(32 \%)]$ & Female $[n=34(68 \%)]$ \\
\hline $20-29$ & 1 & $3($ Mean age $=28)$ \\
$30-39$ & 2 (Mean age $=36)$ & 6 (Mean age $=33.66)$ \\
$40-49$ & 4 (Mean age $=43.75)$ & 6 (Mean age $=42.16)$ \\
$50-59$ & 4 (Mean age $=55.75)$ & 8 (Mean age $=54.12)$ \\
$60-69$ & 5 (Mean age $=66.8)$ & $10($ Mean age $=64)$ \\
70 & 0 & 1 \\
\hline
\end{tabular}


Total of 12 (24\%) patients presented with only low back ache of which $33.33 \%$ (4) were male patients and $66.66 \%$ (8) were female patients. $38(76 \%)$ of the study group presented with low back ache with radiculopathy to lower limb of which 12 (31.57\%) were male patients and $26(68.42 \%)$ were female patients (Table 2).

Table 2: Distribution of patients based on chief complaints at the time of presentation.

\begin{tabular}{|lcc|}
\hline & $\begin{array}{c}\text { Low back pain } \\
\text { only }\end{array}$ & $\begin{array}{c}\text { Low back pain with } \\
\text { radiculopathy }\end{array}$ \\
\hline Men $(\mathrm{n}=16)$ & $4(33.33 \%)$ & $12(31.57 \%)$ \\
Women $(\mathrm{n}=34)$ & $8(66.66 \%)$ & $26(68.42 \%)$ \\
Total $(\mathrm{n}=50)$ & $12(24 \%)$ & $38(76 \%)$ \\
\hline
\end{tabular}

Based on MRI findings, highest of 31 (62\%) patients were found to have intervertebral disc prolapse at L4-L5 levels followed by 14 (28\%) of patients to have Intervertebral disc prolapse at L5-S1 levels and $5(10 \%)$ of patients at L3-L4 level (Table 3).

Table 3: Distribution of levels of disc herniation in patients post MRI.

\begin{tabular}{|lccc|}
\hline & \multicolumn{3}{c|}{ Intervertebral disc herniation level } \\
\cline { 2 - 4 } & L3-L4 & L4-L5 & L5-S1 \\
\hline Men (n=16) & $2(12.5 \%)$ & $8(50 \%)$ & $6(37.5 \%)$ \\
Women (n=34) & $3(8.8 \%)$ & $23(67.64 \%)$ & $8(23.52 \%)$ \\
Total $(\mathrm{n}=50)$ & $5(10 \%)$ & $31(62 \%)$ & $14(28 \%)$ \\
\hline
\end{tabular}

Selective extraforaminal nerve root block was done (Figure 1) and 50 patients were studied of which 50 patients were available for one month post procedure follow up and only 41 patients for 6 months post procedure follow up owing to the coronavirus disease (COVID-19) situation. Telephonic follow up was done to patients who were unable to visit the hospital due to COVID-19 related restrictions. The pre procedure, immediate post procedure, one month follow up and 6 months follow up VAS scores were documented and tabulated.48\% (24) of patients were found to have pre procedure VAS score of 7 with moderate pain; 30\% (15) patients with VAS score of $6 ; 10 \%$ (5) patients with VAS score of 5, 8\% (4) patients with VAS score 8 having severe pain and 2\% (1) patient with highest VAS score of 9 in the study (Table 4).

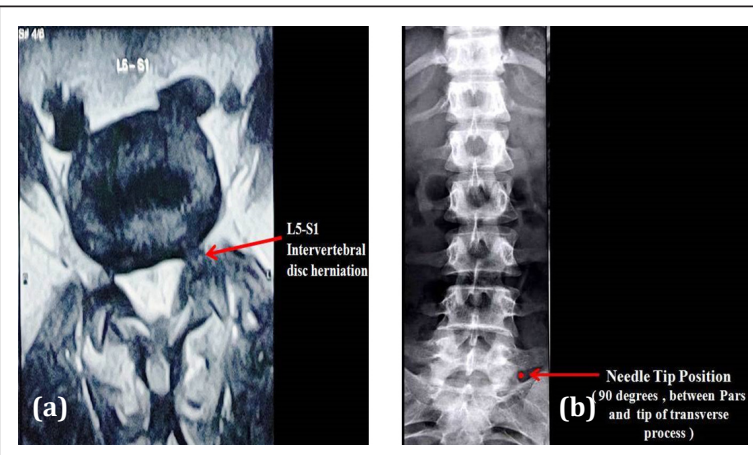

Figure 1: (a) MRI scan showing L5-S1 intervertebral disc herniation, (b) X-ray showing needle tip position in extraforaminal selective nerve root block.

Table 4: Pre procedure, immediate post procedure, one month follow up and 6 months follow up post extraforaminal selective nerve root block VAS scores.

\begin{tabular}{|c|c|c|c|c|}
\hline $\begin{array}{l}\text { VAS } \\
\text { score }\end{array}$ & $\begin{array}{c}\text { Pre } \\
\text { procedure } \\
\text { (n) }\end{array}$ & $\begin{array}{c}\text { Immediate } \\
\text { post } \\
\text { procedure } \\
\text { (n) }\end{array}$ & $\begin{array}{c}\text { one } \\
\text { month } \\
\text { follow up } \\
\text { (n) }\end{array}$ & $\begin{array}{c}6 \text { months } \\
\text { follow up } \\
(n)^{*}\end{array}$ \\
\hline 0 & 0 & 0 & 13 & 25 \\
\hline 1 & 0 & 9 & 21 & 9 \\
\hline 2 & 0 & 21 & 11 & 4 \\
\hline 3 & 0 & 14 & 2 & 1 \\
\hline 4 & 1 & 5 & 2 & 1 \\
\hline 5 & 5 & 1 & 1 & 1 \\
\hline 6 & 15 & 0 & 0 & 0 \\
\hline 7 & 24 & 0 & 0 & 0 \\
\hline 8 & 4 & 0 & 0 & 0 \\
\hline 9 & 1 & 0 & 0 & 0 \\
\hline 10 & 0 & 0 & 0 & 0 \\
\hline $\begin{array}{c}\text { Total } \\
\text { (n) }\end{array}$ & 50 & 50 & 50 & 41 \\
\hline \multicolumn{5}{|c|}{$\begin{array}{l}\text { (n) }{ }^{*} \text { - total number of patients available for follow up at } \\
\text { 6th month post procedure }=41\end{array}$} \\
\hline
\end{tabular}

Immediate post extraforaminal SNRB, highest of $21(42 \%)$ of patients were found to have VAS score of 2, followed by VAS score of 3 among 14 (28\%) patients, VAS score of one in $9(18 \%)$ patients, VAS score of 4 in $5(10 \%)$ patients and VAS score of 5 in $1(2 \%)$ patients. The split data shows changes in the VAS scores of patient from their pre procedure VAS scores and immediate post extraforaminal SNRB VAS scores. It is notable that of the 24 patients who had pre procedure VAS score of 7 , the VAS scores 
reduced to 2 in $62.5 \%$ (15) of the patients and reduced to one in $8.33 \%$ (2) patients. Similarly, of the 15 patients who had pre procedure VAS score of $6,33.33 \%$ (5) patients were found to have post extraforaminal nerve root block VAS score of 1 and 3 each and $26.66 \%(4)$ patients had VAS score of 2. Among the 5 patients who had pre procedure VAS score of 5, 40\% (2) patients had post procedure VAS score of 2 and 3 each and 20\%(1) patient had VAS score of 1 (Table 5).

Table 5: Split data of change in VAS scores of patients immediate post procedure.

\begin{tabular}{|c|c|c|c|c|c|c|c|}
\hline \multirow{2}{*}{$\begin{array}{c}\text { Pre } \\
\text { procedure } \\
\text { VAS score }\end{array}$} & \multirow{2}{*}{$\begin{array}{l}\text { Number of } \\
\text { patients(n) }\end{array}$} & \multicolumn{6}{|c|}{$\begin{array}{c}\text { Immediate post procedure } \\
\text { VAS score }\end{array}$} \\
\hline & & 0 & 1 & 2 & 3 & 4 & 5 \\
\hline 0 & 0 & 0 & 0 & 0 & 0 & 0 & 0 \\
\hline 1 & 0 & 0 & 0 & 0 & 0 & 0 & 0 \\
\hline 2 & 0 & 0 & 0 & 0 & 0 & 0 & 0 \\
\hline 3 & 0 & 0 & 0 & 0 & 0 & 0 & 0 \\
\hline 4 & 1 & 0 & 1 & 0 & 0 & 0 & 0 \\
\hline 5 & 5 & 0 & 1 & 2 & 2 & 0 & 0 \\
\hline 6 & 15 & 0 & 5 & 4 & 5 & 1 & 0 \\
\hline 7 & 24 & 0 & 2 & 15 & 5 & 2 & 0 \\
\hline 8 & 4 & 0 & 0 & 0 & 2 & 1 & 0 \\
\hline 9 & 1 & 0 & 0 & 0 & 0 & 1 & 1 \\
\hline \multirow[t]{2}{*}{10} & 0 & 0 & 0 & 0 & 0 & 0 & 0 \\
\hline & Total $(n)=50$ & 0 & 9 & 21 & 14 & 5 & 1 \\
\hline
\end{tabular}

DecreaseinVASscoresimmediatepostextraforaminal SNRB by 5 or more points (excellent) in 25\% (25) patients; by 3-4 points (good) in 44\% (22) patients and by $1-2$ point (fair) in $6 \%$ (3) patients. No increase in immediate post procedure VAS scores were found (Table 6).

One month follow up showed highest of 21 (42\%) patients to have VAS score of one followed by VAS score of 0among 13(26\%) patients; VAS score of one in $11(22 \%)$ patients; VAS score of 4 and 5 in $2(4 \%)$ patients each. The split data shows changes in the VAS scores of patient from their immediate post procedure to one month post extraforaminal SNRB VAS scores. Among the 21 patients who had immediate post procedure VAS score of 2 , in $85.71 \%$ (18) patients, the pain score improved to one. Among the 14 patients who had immediate post procedure VAS score of 3, in $64.28 \%$ (9) patients, the pain score improved to 2 . In 5 patients who had immediate post procedure VAS score of 4,VAS score improved to 0,2 in $20 \%$ (1); improved to 3 in $40 \%$ (2) patients and remained the same in $20 \%$ (1) patients. Pain scores worsened only in one patient who had immediate post procedure VAS score of one to VAS score of 2 (Table 7).

Table 6: Distribution of changes in VAS scores of patients immediate post procedure.

\begin{tabular}{|lc|}
\hline VAS score immediate post procedure & Number of patients \\
\hline Decrease in VAS score & $25(25 \%)$ \\
5 or more points (excellent) & $22(44 \%)$ \\
$3-4$ points (good) & $3(6 \%)$ \\
1-2 points (fair) & 0 \\
None (poor) & \\
Increase in VAS score & 0 \\
1-2 points (bad) & 0 \\
$3-4$ points (worse) & 0 \\
5 or more points (worst) & \\
\hline
\end{tabular}

Table 7: Split data of changes in VAS scores of patients one month after procedure.

\begin{tabular}{|c|c|c|c|c|c|c|c|}
\hline \multirow{2}{*}{$\begin{array}{c}\text { Immediate } \\
\text { post } \\
\text { procedure } \\
\text { VAS Score }\end{array}$} & \multirow{2}{*}{$\begin{array}{l}\text { Number of } \\
\text { patients (n) }\end{array}$} & \multicolumn{6}{|c|}{$\begin{array}{c}\text { One month post procedure } \\
\text { VAS score }\end{array}$} \\
\hline & & 0 & 1 & 2 & 3 & 4 & 5 \\
\hline 0 & 0 & 0 & 0 & 0 & 0 & 0 & 0 \\
\hline 1 & 9 & 8 & 1 & 0 & 0 & 0 & 0 \\
\hline 2 & 21 & 2 & 18 & 1 & 0 & 0 & 0 \\
\hline 3 & 14 & 2 & 2 & 9 & 0 & 1 & 0 \\
\hline 4 & 5 & 1 & 0 & 1 & 2 & 1 & 0 \\
\hline 5 & 1 & 0 & 0 & 0 & 0 & 0 & 1 \\
\hline 6 & 0 & 0 & 0 & 0 & 0 & 0 & 0 \\
\hline 7 & 0 & 0 & 0 & 0 & 0 & 0 & 0 \\
\hline 8 & 0 & 0 & 0 & 0 & 0 & 0 & 0 \\
\hline 9 & 0 & 0 & 0 & 0 & 0 & 0 & 0 \\
\hline \multirow[t]{2}{*}{10} & 0 & 0 & 0 & 0 & 0 & 0 & 0 \\
\hline & Total $(\mathrm{n})=50$ & 13 & 21 & 11 & 2 & 2 & 1 \\
\hline
\end{tabular}

Decrease in VAS scores as compared to immediate post procedure VAS scores at one month post 
extraforaminal SNRB was found in 6\% (3) patients (excellent) by 3-4 points and $84 \%$ (42) patients by 1-2 points (fair). No change in VAS score (poor) was found only in 8\% (4) patients along with increase in the VAS scores by $1-2$ points (bad) in $2 \%$ (1) patient (Table 8).

Table 8: Distribution of changes in VAS scores of patients one month post procedure.

\begin{tabular}{|lc|}
\hline VAS score at one month post procedure & $\begin{array}{c}\text { Number of } \\
\text { patients }\end{array}$ \\
\hline Decrease in VAS score & \\
5 or more points (excellent) & 0 \\
$3-4$ points (good) & $3(6 \%)$ \\
$1-2$ points (fair) & $42(84 \%)$ \\
Increase in VAS score & \\
None (poor) & $4(8 \%)$ \\
$1-2$ points (bad) & $1(2 \%)$ \\
$3-4$ points (worse) & 0 \\
5 or more points (worst) & 0 \\
\hline
\end{tabular}

Six months follow up included only 41 patients were available for follow up owing to the COVID circumstances and showed highest of 25 (60.97\%) patients to have VAS score of 0 followed by VAS score of one among $8(19.51 \%)$ patients; VAS score of 2 in $4(48.78 \%)$ patients and VAS score of 3,4,5 in 1 (24.39\%) patients each.

The split data shows changes in the VAS scores of patient from their one month post procedure to 6 months post extraforaminal SNRB VAS scores. Among 13 patients who had their VAS score 0 , no change in VAS score was found. Out of 12 patients with one month post procedure VAS score $1,8(66.66 \%)$ patients were found to have improved VAS scores to 0 . No change of VAS scores were noted in $5(12.19 \%)$ of the 41 patients other than those who had VAS score $0.3^{\text {rd }}$ month extraforaminal selective nerve block was given in 2 patients who had VAS score of 3 ; 1 patient who had VAS score of 4 and 1 patient who had VAS score of $5.6^{\text {th }}$ month VAS scores in them changed to 0, 0 and 1 respectively (Table 9).

Significant increase in the 6 months post procedure VAS scores as compared to 1 month post procedure VAS scores was noted. Increase in the VAS scores by $3-4$ points (worse) in $2.43 \%$ (1) patient; by $1-2$ points (bad) in $7.31 \%$ (3) patients. No change (poor) in the VAS scores was found in $12.19 \%$ (5) patients. Even then, no change in VAS score of 0 was documented in $31.70 \%$ (13) of the patients. $36.58 \%$ (15) patients showed 1-2 points (fair), 9.75\% (4) patients showed 3-4 points(good) decrease in VAS scores as well (Table 10).

Table 9: Split data of changes in VAS scores of patients 6 months after procedure.

\begin{tabular}{|c|c|c|c|c|c|c|c|c|}
\hline \multirow{2}{*}{$\begin{array}{l}\text { One month post } \\
\text { procedure VAS } \\
\text { Score }\end{array}$} & \multirow{2}{*}{$\begin{array}{l}\text { Number of } \\
\text { patients(n) }\end{array}$} & \multirow{2}{*}{$\begin{array}{c}\text { corrected number } \\
\text { of patients }(n)^{*}\end{array}$} & \multicolumn{6}{|c|}{6 month post procedure VAS score } \\
\hline & & & 0 & 1 & 2 & 3 & 4 & 5 \\
\hline 0 & 13 & 13 & 13 & 0 & 0 & 0 & 0 & 0 \\
\hline 1 & 21 & 12 & 8 & 3 & 1 & 0 & 0 & 0 \\
\hline 2 & 11 & 11 & 1 & 5 & 2 & 1 & 1 & 1 \\
\hline 3 & 2 & 2 & 2 & 0 & 0 & 0 & 0 & 0 \\
\hline 4 & 2 & 2 & 1 & 0 & 1 & 0 & 0 & 0 \\
\hline 5 & 1 & 1 & 0 & 1 & 0 & 0 & 0 & 0 \\
\hline 6 & 0 & 0 & 0 & 0 & 0 & 0 & 0 & 0 \\
\hline 7 & 0 & 0 & 0 & 0 & 0 & 0 & 0 & 0 \\
\hline 8 & 0 & 0 & 0 & 0 & 0 & 0 & 0 & 0 \\
\hline 9 & 0 & 0 & 0 & 0 & 0 & 0 & 0 & 0 \\
\hline \multirow[t]{2}{*}{10} & 0 & 0 & 0 & 0 & 0 & 0 & 0 & 0 \\
\hline & Total $=50$ & Total $=41$ & 25 & 8 & 4 & 1 & 1 & 1 \\
\hline
\end{tabular}

$\mathrm{n}^{*}=$ Total number of patients available for follow up at $6^{\text {th }}$ month $=41$ 
Table 10: Distribution of changes in VAS scores of patients 6 months post procedure.

\begin{tabular}{|lc|}
\hline VAS score at 6 month procedure & Number of patients \\
\hline Decrease in VAS score & 0 \\
5 or more points (excellent) & $13(31.70 \%)$ \\
none (VAS=0, excellent) & $4(9.75 \%)$ \\
3-4 points (good) & $15(36.58 \%)$ \\
$1-2$ points (fair) & \\
Increase in VAS score & $5(12.19 \%)$ \\
VAS same as previous follow up & $3(7.31 \%)$ \\
(poor) & $1(2.43 \%)$ \\
1-2 points (bad) & 0 \\
$3-4$ points (worse) & \\
5 or more points(worst) & \\
\hline
\end{tabular}

\section{Discussion}

Majority of the patients who presented with lower back ache were females (68\%) which is similar to the results found in several researches directed towards studying the prevalence of lower back ache and radiculopathy to lower limbs in males and females and also agrees with the results of mean age groups found to be affected [21, 22]. L4-L5 intervertebral disc herniation was observed to be the most common level of disc herniation causing the lumbar pain and radiculopathy ( $62 \%$ ) and goes hand in hand with the fact very well established in the existing literature. A study concluded that there was no significant differences in the outcomes when patients with sciatica were treated with early surgery to when patients were treated conservatively for prolonged time [5] and in such circumstances, SNRB is the best treatment of choice for pain relief, either as a choice for early intervention or in cases of failure of conservative methods of management. Given a choice for early SNRB or early surgeries, SNRB is better option for pain relief, with lesser risks. Combination of steroid and local anesthetic to be instilled in SNRB was made on easy availability and feasibility of the patient to afford it, and in this study, $2 \mathrm{ml}(80$ $\mathrm{mg}$ ) of methylprednisolone (Depo-medrol) with 1 $\mathrm{ml} 2 \%$ plain lignocaine was used. A study showed that betamethasone has a more powerful antiinflammatory effect [23] though a comparative study made on combination $3 \mathrm{ml}$ of betamethasone $6 \mathrm{mg}$ with $5 \mathrm{ml}$ of $5 \%$ lidocaine and $1 \mathrm{ml}$ of triamcinolone $60 \mathrm{mg}$ with $5 \mathrm{ml}$ of bupivacaine found no differences as to the drug used to perform the nerve root block [24]. Based on the literature, it is considered that the use of a local anesthetic and a steroid is the first choice, regardless of the origin or the drug class. Several approaches to administer SNRB is found in literature, each of it has its own therapeutic effects [16]. Most of the published researches on SNRB fails to specify the precise needle tip location at the time of injection. Even if explained, most of them fail to define if root block is administered at pathological vertebral level, or at the exiting nerve root. In our study, based on the type of herniation of the disc, the appropriate choice was made.

Our study showed statistically significant changes in the VAS scores of patients post extraforaminal SNRB $(\mathrm{p}<0.001)$. A study made on extraforaminal cervical SNRB for cervical radiculopathy concluded that extraforaminal approach is safest protocol for cervical SNRB and was found to have similar results [25]. Generally, it is considered that the immediate pain relief post SNRB is due to the local anesthetics administered which is short acting and wears off within several hours whereas the steroid takes about two to three days to start acting and its effects generally persists for few days to several months [3]. Decrease in VAS scores immediate post extraforaminal SNRB was excellent in $25 \%$ of the study group with 5 or more point reduction of VAS scores and good in $44 \%$ with 3-4 points reduction. It is also to be noted that not a single case showed change nor increase in their VAS scores immediate post procedure. This suggests that extraforaminal approach is successful choice of SNRB in cases of lumbar radiculopathy with excellent immediate pain relief. One month post procedure VAS scores of the patients assessed showed statistically significant results $(p<0.005)$ owing to change in of VAS score by $1-2$ points in $84 \%$ (42) patients and no change or increase in the VAS scores only in $5(10 \%)$ patients. This suggests recurrence of the symptoms one month post extraforaminal nerve root block is a possibility along with chances of worsening of symptoms even though the procedure provides excellent results at end of one month. This further proves that excellent immediate post procedure results were not only due to the effects of the local anesthetics used. Detailed study on effect of Steroids alone in such would produce a better results and understanding the significance of steroid alone in SNRBs. Increase in the 6 months post procedure VAS scores as 
compared to one month post procedure VAS scores was noted and was not found to be statistically significant $(\mathrm{p}=0.2)$. No change or increase in the VAS scores in $9(21.95 \%)$ patients may be due to several factors. Patient compliance to post procedure orders, daily activities of the patient and instances of unnoticed blunt trauma can be some of the causes that might result in denovo mechanical compression and be associated with increased VAS scores even if detailed and thorough history is taken on follow up. A study appreciates this by concluding that chances of recurrence of pain was more in case of mechanical compression of the nerves than in those patients who had disc herniation alone [26]. Further studies on factors such as patient to patient variability on bioavailability of steroids, pharmacokinetics and pharmacodynamics of the drug instilled in different age group would provide better data to substantiate results of our study. No change of VAS score of 0in $13(31.70 \%)$ at one month and 6 months post procedure,1-2 points decrease in $36.58 \%$ (15) and3-4 points decrease in $9.75 \%$ (4) shows that extraforaminal SNRB is excellent as long term therapeutic modality and was found to be statistically significant $(\mathrm{p}<0.005) .8 \%$ (4) patients among the study group underwent a repeat extraforaminal SNRB at the third month post first procedure and found to have 3-4 points reduction in VAS score after 3 months ( 6 months post first procedure). This shows that repeating extraforaminal SNRB in patients with minimal change and/or increased VAS score post one month procedure would show consistent reduction or better results for pain management. At the end of $6^{\text {th }}$ month follow up, among the patients with mild-moderate and moderate-severe pain (total of 9 patients), $12.19 \%$ (5) patients needed no further treatment based on clinical evaluation. Two patients needed conservative management or further SNRB based on their compliance and clinical assessment and only 2 patients needed further surgical intervention based on clinical assessment and repeat MRI. None of the patients had any sensory or motor defecits post procedure. L3, L4, L5, S1 dermatomal disturbances present preoperatively were found to be satisfactorily reduced in all patients post procedure by the end of 6 months of follow up. We don't deny the fact that inability to follow up 9 patients at six months post procedure plays a crucial role in our study results even after statistically correcting the data. Successive follow up of these patients would provide further information on effectiveness of extraforaminal SNRB.

\section{Conclusion}

Our study concludes that extraforaminal SNRB shows excellent results immediate post procedure for management of lumbar radiculopathy in lumbar intervertebral disc prolapse. Significant reduction in VAS scores immediate post procedure suggests it can be used as treatment of choice for immediate pain management in patients and as a diagnostic tool to confirm the cause of lumbar radiculopathy or in patients with failure of conservative management as intermediary treatment modality. The procedure is successful in acting as excellent long term therapeutic modality for lumbar radiculopathy with statistically significant reductions in pain scores at one month and 6 months follow-up. Significant increase in the pain scores at $6^{\text {th }}$ month shows that recurrence of symptoms is a possibility and further randomized control studies with larger study population and association of patient factors to evaluate effectiveness of extraforaminal SNRB would give better insight and knowledge of the factual data.

\section{Conflicts of interest}

Authors declare no conflicts of interest.

\section{References}

[1] Cassidy JD, Carroll LJ, Cote P. The Saskatchewan health and back pain survey: The prevalence of low back pain and related disability in Saskatchewan adults. Spine.1998; 23(17):1860-1866.

[2] Chung JY, Yim JH, Seo HY, Kim SK, Cho KJ. The efficacy and persistence of selective nerve root block under fluoroscopic guidance for cervical radiculopathy. Asian Spine J. 2012; 6(4):227-232.

[3] Anderberg L, Annertz M, Persson L, Brandt L, Saveland H. Transforaminal steroid injections for the treatment of cervical radiculopathy: a prospective and randomised study. Eur Spine j. 2007; 16(3):321-328.

[4] Narozny M, Zanetti M, Boos N. Therapeutic efficacy of Selective Nerve Root Blocks in the treatment of lumbar radicular leg pain. Swiss Med Weekly. 2001; 131(5-6):7580.

[5] Jacobs WC, Van TM, Arts M, Rubinstein SM, Middelkoop MV, et al. Surgery versus conservative management of sciatica due to a lumbar herniated disc: a systematic review. Eur Spine j. 2011; 20(4):513-522.

[6] Zaina F, Tomkins-Lane C, Carragee E, Negrini S. Surgical versus non-surgical treatment for lumbar spinal stenosis. Cochrane Database Syst Rev. 2016; 2016(1):CD010264CD010264.

[7] Wenger HC, Cifu AS.Treatment of low back pain.JAMA. 2017; 318(8):743-744.

[8] Chou R, Loeser JD, Owens DK, Rosenquist RW, Atlas SJ, et al. Interventional therapies, surgery, and interdisciplinary rehabilitation for low back pain: an evidence-based clinical practice guideline from the American Pain Society. Spine. 2009; 34(10):1066-1077. 
[9] Koes BW,van Tulder MW,Peul WC. Diagnosis and treatment of sciatica.BMJ (Clinical Research Ed). 2007; 334(7607):13131317.

[10] Stafford MA, Peng P, Hill DA. Sciatica: a review of history, epidemiology, pathogenesis, and the role of epidural steroid injection in management. Br J Anaesth. 2007; 99(4):461473.

[11] Alexander CE, Varacallo M. Lumbosacral Radiculopathy. 2021.

[12] Clark AJ, Safaee MM, Khan NR, Brown MT, Foley KT. Tubular microdiscectomy: techniques, complication avoidance, and review of the literature. Neurosurg Focus. 2017; 43(2):E7.

[13] Skovrlj B, Gilligan J, Cutler HS, Qureshi SA. Minimally invasive procedures on the lumbar spine. World j Clin Cases. 2015; 3(1):1-9.

[14] Arun-Kumar K, Jayaprasad S, Senthil K, Lohith H, Jayaprakash KV. The outcomes of Selective Nerve Root Block for disc induced lumbar radiculopathy. Malaysian Orthopaedic J. 2015; 9(3):17-22.

[15] Beynon R, Elwenspoek MMC, Sheppard A, Higgins JN, Kolias AG, et al. The utility of diagnostic Selective Nerve Root Blocks in the management of patients with lumbar radiculopathy: a systematic review. BMJ Open. 2019; 9(4):e025790.

[16] Pfirrmann CW, Oberholzer PA, Zanetti M, Boos N, Trudell DJ, et al. Selective nerve root blocks for the treatment of sciatica: Evaluation of injection site and effectiveness - a study with patients and cadavers. Radiology. 2001; 221(3):704-711.

[17] Mobaleghi J, Allahdini F, Nasseri K, Ahsan B, Shami S, et al. Comparing the effects of epidural methylprednisolone acetate injected in patients with pain due to lumbar spinal stenosis or herniated disks: a prospective study. Int J Gen Med. 2011; 4:875-878.

[18] Blankenbaker DG, De Smet AA, Stanczak JD, Fine JP. Lumbar radiculopathy: Treatment with selective lumbar nerve blocks- comparison of effectiveness of triamcinolone and betamethasone injectable suspensions. Radiology. 2005; 237:738-741.

[19] Lee JW, Kim SH, Choi JY, Yeom JS, Kim KJ, et al. Transforaminal epidural steroid injection for lumbosacral radiculopathy: preganglionic versus conventional approach. Korean J Radiol. 2006; 7(2):139-144.

[20] Weiner BK, Fraser RD. Foraminal injection for lateral lumbar disc herniation. J Bone Joint Surg Br. 1997; 79(5):804-807.

[21] Yi XJW, Jun-Qing W, Zoltan K. Increased low back pain prevalence in females than in males after menopause age: evidences based on synthetic literature review. 2016; 6(2): 199-206.

[22] Frymoyer JW, Pope MH, Costanza MC, Rosen JC, Goggin JE, et al. Epidemiologic studies of low-back pain. Spine. 1980; 5(5):419-423.

[23] Schimmer BP, Parker KL. Adrenocorticotropic hormone, adrenocortical steroids and their synthetic analogs: inhibitors of the synthesis and actions of adrenocortical hormones. In: Hardman JG, Limbird LE, Gilman AG, eds. The Pharmacological Basis of Therapeutics. 10th ed. New York, NY: McGraw-Hill; 2001:1649-1677.

[24] Juan PG. Lumbar selective nerve root block: Comparative study using two pharmacological formulae. Global Spine Journal. 2018; 8(4):374-377.

[25] Shawn R, Jiang W. Extraforaminal cervical selective nerve root block-description of a posterolateral approach with cone beam-based CT guidance. Pain Pract. 2020; 20(8):919928.
[26] Kanayama M, Oha F, Hashimoto T. What types of degenerative lumbar pathologies respond to nerve root injection? A retrospective review of six hundred and forty one cases. Int Orthop. 2005; 39(7):1379-1382. 